\title{
A RESOLUÇÃODE CONFLITOS ESTRUTURAIS NO SISTEMA MULTIPORTAS DE ACESSO À JUSTIÇA
}

\author{
THE RESOLUTION OF STRUCTURAL CONFLICTS IN THE MULTIDOOR \\ COURTHOUSE SYSTEM
}

\author{
Carlos Eduardo Montes Netto ${ }^{1}$ \\ Jonathas Celino Paiola ${ }^{2}$ \\ Olavo Augusto Vianna Alves Ferreira ${ }^{3}$
}

\section{RESUMO}

O aumento da judicialização tem representado um desafio para a obtenção de decisões céleres, eficientes e justas no âmbito justiça estatal. $\mathrm{O}$ presente estudo busca analisar, diante da escassez de pesquisas sobre o assunto, as possibilidades oferecidas pelo sistema multiportas para a resolução de problemas estruturais, que demandam a reorganização de toda uma estrutura, pública ou privada, não raras vezes de ambas, exigindo a adoção de soluções estruturais, por meio de um processo estrutural. Optou-se pela realização de uma pesquisa exploratória com a utilização de revisão bibliográfica e da análise qualitativa dos dados a fim de se cumprir esse objetivo, verificando-se que, considerando as nuances dos problemas estruturais, de múltiplos aspectos, inclusive patrimoniais e disponíveis, a eleição da porta mais adequada de acesso à justiça, ou até uma combinação delas, pode ser benéfica ao contemplar maior eficiência e celeridade no acesso à justiça.

Palavras-chave: Problemas estruturais. Sistema multiportas. Acesso à justiça.

\section{ABSTRACT}

The increase in judicialization has represented a challenge for obtaining quick, efficient and fair decisions within the scope of the state justice system. This study seeks to analyze, given the lack of research on the subject, the possibilities offered by the Multidoor Courthouse System for solving process problems, which require a reorganization of an entire structure, or private, often both, requiring a adoption of proposed solutions through a structural process. It was decided to carry out an exploratory research using a literature review and qualitative data analysis in order to achieve this objective, verifying that, considering the nuances of structural problems, of multiple aspects, including property and available, the choice of the most ad equate access to justice, or even a combination of them, can be beneficial by contemplating greater efficiency and speed in access to justice.

Keywords: Structural problems. Multidoor Courthouse System. Access to justice.

\footnotetext{
${ }^{1}$ Doutorando e mestre em Direitos Coletivos e da Cidadania pela UNAERP, Ribeirão Preto-SP (Brasil). Professor de cursos de graduação e de pós-graduação. Juiz de Direito do Estado de São Paulo

${ }^{2}$ Professor do Curso de Especia lização em Direito Civil e Processo Civil da UNAERP. MBA em Finanças, Controladoria e Auditoria pela Faculdade Getúlio Vargas (FGV). Pós-graduado em Direito Constitucionale em Direito Tributário pela Universidade Estácio de Sá

${ }^{3}$ Professor Titular do Programa de Pós-Graduação em Mestrado e Doutorado da Universidade de Ribeirão Preto UNAERP (Brasil). Doutor e mestre em Direito pela Pontifícia Universidade Católica de São Paulo - PUC/SP. Procura dor do Esta do de São Paulo. Membro da Comissão Especial de Arbitra gem do Conselho Federal da OAB. Membro de listas referenciais de árbitros. Sócio da CAMES.
} 


\section{INTRODUÇÃ̃}

Segundo Didier Júnior e Zaneti Júnior (2021) os denominados processos estruturais apresentam como características a multipolaridade, consistente na: i) formação de diversos polos de opiniões sobre o conflito estrutural, contrapondo-se ao processo individual (binário), que envolve apenas os interesses do autor e do réu; ii) coletividade do processo, com a discussão de uma situação jurídica coletiva, que pode envolver direitos difusos, coletivos ou individuais homogêneos, com efeitos que se projetam para a coletividade; iii) complexidade, diante da impossibilidade de resolução do problema pela adoção de uma única medida, além de demandar a participação de diversos atores para que atinja o seu objetivo.

E mais, o percurso do processo estrutural deve observar diversas fases de desenvolvimento, que vão desde o diagnóstico da situação até a implementação de um plano de atuação, que deve ser revisto e constantemente ad aptado às características do conflito estrutural, promovendo-se uma "reestruturação institucional" (structural injuction), consubstanciada num conjunto de medidas que visam, precipuamente, a reorganização de uma estrutura, a fim de reduzir ou eliminar a ocorrência da violação de direitos.

Nessa perspectiva, pretende-se investigar, sem a menor pretensão de se esgotar o assunto, indicando-se, inclusive, a necessidade da realização de outros estudos mais específicos, as possibilidades que o sistema multiportas de acesso à justiça oferece para a resolução dos conflitos estruturais que envolvem múltiplos aspectos, inclusive patrimoniais e disponíveis, considerando que o próprio Conselho Nacional de Justiça (CNJ), por meio da Resolução $\mathrm{n}^{\circ}$ 125, de 29 de novembro de 2010 (BRASIL, 2010a), reconhece que o acesso à justiça previsto no art. $5^{\circ}, \mathrm{XXXV}$, da Constituição da República Federativa do Brasil de 1988 (CRFB/88), além da vertente formal perante os órgãos judiciários, implica em acesso à ordem jurídica justa, incluindo outros instrumentos efetivos de pacificação social, como conciliação e a mediação.

A pesquisa se justifica pela existência de diversas espécies de conflitos estruturais no ordenamento jurídico brasileiro, desde questões envolvendo a recuperação judicial, a falência, a liquid ação extrajudicial e a reestruturação de empresas, até processos coletivos em sentido amplo, que tratam de direitos difusos, coletivos em sentido estrito e individuais homogêneos, com amplo alcance prático e teórico, bem como pela escassez de estudos específicos sobre as possíveis soluções que o sistema multiportas de acesso à justiça oferece para a resolução desse tipo de controvérsias. 


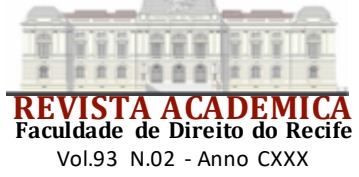

Buscand o alcançar o objetivo pretendido por meio de uma análise qualitativa do contexto, para este estudo optou-se pela realização de uma pesquisa exploratória, por meio de revisão bibliográfica, com ênfase nas dimensões doutrinária, normativa e jurisprudencial que envolvem a interpretação da CRFB/88, de normas infraconstitucionais, valendo-se da análise de julgados do Supremo Tribunal Federal (STF), do Superior Tribunal de Justiça (STJ) e de out ros tribunais, além de livros e artigos científicos.

O presente trabalho abordará a fundamentação teórica envolvendo o processo estrutural, incluindo suas origens e características, a implementação das decisões estruturais, exemplos práticos de problemas estruturais, a inadequação da resolução de problemas estruturais por meio de processos individuais, a legitimidade do Poder Judiciário na condução do processo estrutural e as possibilidades que o sistema multiportas oferece para a solução desses conflitos pela via extrajudicial, como o compromisso de ajustamento de conduta, a recomendação, o procedimento administrativo, a conciliação e a mediação.

\section{PROCESSO ESTRUTURAL}

O processo estrutural, segundo Vitorelli (2021, p. 64), pode ser compreendido como "um processo coletivo no qual se pretende, pela atuação jurisdicional, a reorganização de uma estrutura, pública ou privada, que causa, fomenta ou viabiliza a ocorrência de uma violação de direitos, pelo modo como funciona, originando um litígio estrutural".

Didier Júnior e Zaneti Júnior (2021, p. 586) afirmam que para compreender o processo estrutural, necessário se fazentender o que se denomina problema estrutural, que pode ser definido com uma "[...] situação de ilicitude contínua e permanente ou uma situação de desconformidade, ainda que não propriamente ilícita, no sentido de ser uma situação que não corresponde ao estado de coisas considerado ideal."

Para os autores, esse estado de desconformidade não pode ser considerado um estado de ilicitude, porquanto a desorganização estrutural pode decorrer tanto de um ato lícito quanto ilícito. Como exemplo, pode ser citada a pandemia provocada pela COVID-19, que, no Brasil, desencadeou diversos problemas estruturais, a exemplo da necessidade reorganização do sistema de saúde para o atendimento de uma nova demanda hospitalar abrupta e específica (DIDIER JÚNIOR; ZANETI JÚNIOR, 2021).

O instituto também não pode ser compreendido apenas a partir da complexidade do problema, em que pese os maiores exemplos de processos dessa natureza decorrerem de questões altamente complexas, tampouco que resulta, inevitavelmente, no ajuizamento de uma ação 


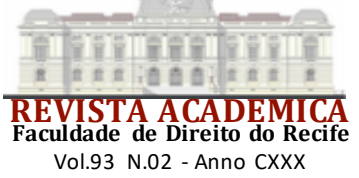

coletiva, notadamente por ser possível a implementação de medidas estruturantes extrajudiciais, como será, posteriormente, debatido.

É possível citar, como exemplo de processos estruturais, as demandas que visam a assegurar o direito à saúde no Brasil. Ante a omissão estatal na implementação das políticas públicas, o Poder Judiciário tem sido provocado a se pronunciar a respeito de diversos temas sensíveis, colmatando as omissões inconstitucionais dos órgãos estatais (BRASIL, 2011), que devem ser repelidas, ao adotar medidas tendentes a restaurar a norma fundamental violada pela inércia do poder estatal (BRASIL, 2006).

A decisão do STF no julgamento do RE 566.471 (BRASIL, 2007b), que trata do tema relativo ao fornecimento de remédios de alto custo não disponíveis no SUS, é um exemplo típico de processo estrutural, na medida em que reflete um problema presente na sociedade, em que diversos indivíduos, acometidos de doenças graves, não têm o tratamento adequad o fornecido pelo poder público, haja vista o alto custo do seu tratamento e o reduzido grau de comprometimento pelos gestores públicos.

A implementação de políticas públicas no tocante a essas doenças demanda, ainda, a discussão a respeito da eficácia dos tratamentos, envolvendo não apenas os gestores, mas, também, pesquisadores, fornecedores, muitas vezes estrangeiros, técnicos das agências reguladoras - como é o caso da ANVISA, que faz a análise e registro dos produtos -, de médicos, enfermeiros, do estabelecimento de protocolos, dos poderes Executivo e Legislativo, além do Judiciário, diante da possibilidade de fornecimento por meio de uma decisão judicial.

\subsection{ORIGEM}

O processo estrutural tem sua origem no caso Brown v. Board of Education, de 1954, julgado pela Suprema Corte dos Estados Unidos. Para compreender a relevância deste julgamento, faz-se necessário revisitar a história dajurisprudência norte americana relativa à segregação racial.

O primeiro julgamento marcante corresponde ao caso Dred Scott V. Sanford, 1857. Dred Scott era um escravo que havia trabalhad o tanto em estados em que era permitida, como em estados em que era proibida a escravidão. Por esse motivo, ajuizou ação em face da senhora Emerson, sustentando a tese de que, tendo trabalhado em estados livres, deveria ser reconhecida a sua liberdade, haja vista que once free, always free (uma vez libre, sempre livre).

Na primeira instância, reconheceu-se o direito pleiteado por Dred. Contudo, a senhora Emerson transferiu ao seu irmão Stanford a gestão dos negócios. Como resultado, este apelou e a Corte Estadual negou a liberdade a Dred. Este interpôs recurso perante a Suprema Corte, que, sob 


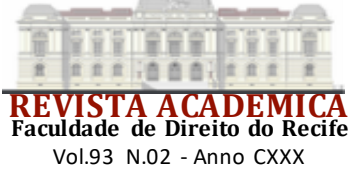

público, praias, piscinas, hotéis. Trata-se do primeiro caso a envolver falhas estruturais que violam direitos fundamentais, na medida em que a decisão, de per si, não era apta a implementar a política de não-discriminação, notadamente pela resistência dos setores públicos e privados na resolução da questão ${ }^{6}$.

Por esse motivo, em novo julgamento da controvérsia a Suprema Corte decidiu adotar medidas que eliminassem essas disfunções institucionais (ARENHART, 2014), mas, dessa vez, de forma progressiva, a partir da elaboração de alguns planos de ações que seriam acompanhadas pelo Judiciário local.

Não obstante a Suprema Corte americana tenha reconhecido a ilegalidade da segregação racial nas escolas, não detalhou as medidas que deveriam ser adotadas, expedindo, apenas, ordens aos juízos de origem para que ad otassem as providencias compatíveis com o julgamento.

\section{A IMPLEMENTAÇÃO DAS DECISÕES NO PROCESSO ESTRUTURAL}

A implementação das decisões no processo estrutural decorrerá de ordens judiciais que imporão obrigações de fazer ou não fazer aos indivíduos responsáveis, sobretudo, pela instituição que se almeja reestruturar. Didier Júnior e Zaneti Júnior (2021, p. 591) asseveram que a decisão estrutural "é aquela que, partindo da constatação de um estad o de desconformidade, estabelece o estado ideal de coisas que se pretende seja implementado (fim) e o modo pelo qual esse resultado deve ser alcançado (meios)". Referida decisão terá um conteúdo aberto - é dizer, qual o resultado que deverá ser alcançado -, e descreverá o modo pelo qual o resultado será obtido ${ }^{7}$.

Exemplificativamente, o STF, no julgamento da PET3.388 (BRASIL, 2013), que tratou do caso da Raposa Serra do Sol, que, a despeito de reconhecer a demarcação das terras em benefício do grupo indígena, estabeleceu diversas condições para o seu exercício. Registre-se que foram opostos diversos Embargos de Declaração em face da decisão, dentre os quais o oposto pela Procuradoria Geral da República (PGR) que questionou a validade das condicionantes incorporadas ao acórdão. No entanto, o ministro Roberto Barroso concordou que a incorporação das salvaguardas foi uma decisão atípica, mas ressaltou que, sem elas, seria impraticável pôr fim

\footnotetext{
${ }^{6}$ Podem ser citadas outras ações cujo intento é o de alterar o funcionamento de instituições públicas por meio do processo estrutural, tais como o sistema de saúde, o funcionamento de escolas e creche $\mathrm{s}$ ou o sistema prisional. (VITORELLI, 2018, p. 1282).

${ }^{7}$ Segundo Didier Júnior e Zaneti Júnior (2021), a estrutura da sentença que conteúdo aberto se assemelha a uma norma-princípio enquanto que a que descreve o modo pelo qual será obtida se assemelha a uma norma-regra.
} 


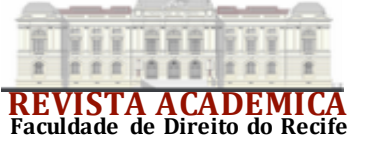

Vol.93 N.02 - Anno CXXX

ao conflito existente na região. Destarte, as salvaguardas foram uma espécie de regime jurídico a ser seguido para a execução da decisão.

Isso porque a maioria entendeu que não era possível pôr fim ao conflito fundiário e social que lhe foi submetido sem enunciar os aspectos básicos do regime jurídico aplicável à área demarcada.

\subsection{EXEMPLOS PRÁTICOS NO BRASIL}

Didier Júnior, Zaneti Júnior e Oliveira (2017) defendem que o processo falimentar seja um processo estrutural, haja vista o conteúdo da sentença de decretação da falência, previsto no artigo 99 da Lei n ${ }^{\text {11 }}$ 11.101/2005 (BRASIL, 2005a). Vitorelli (2021), por sua vez, sustenta que o melhor exemplo de processo estrutural seria o processo da recuperação judicial, porquanto o juiz, o administrador judicial, os credores e a própria empresa visam a um mesmo objetivo, qual seja a preservação da atividade empresarial e ao pagamento das dívidas. O processo se desenvolve a partir da elaboração de um plano de recuperação judicial, que conta com a participação dos credores, com o auxílio do administrador judicial e a fiscalização por parte do magistrado.

Outro exemplo é o Conselho Administrativo deDefesa Econômica (CADE), que determina medidas de reestruturação de empresas, como o ocorrido com a fusão da Sadia e da Perdigão, em que se determinou, v.g., a alienação da Rezende, da Fiesta, da Doriana e da Delicata.

A operação Lava-Jato também pode ser citada como exemplo da adoção de medidas estruturais, mediante os acordos de leniência, já que diversas empresas assumiram obrigações de reestruturarem os seus processos internos, a fim de evitar a reiteração desses comportamentos.

\section{PROBLEMAS ESTRUTURAIS RESOLVIDOS COMO PROCESSOS INDIVIDUAIS}

Considerando que a resolução de processos estruturais é complexa, longa e que demanda a participação de diversos atores na condução do problema, tem se preferido a resolução individual de conflitos estruturais. Exemplificativamente, todos os anos são ajuizadas milhares de ações judiciais pleiteando vagas para as crianças em creches. No entanto, o tratamento correto desse problema estrutural seria justamente um processo estrutural.

Essa postura acarreta uma outra violação: quem pleiteia primeiro o benefício será atendido, ficando as demais crianças sem a vaga na creche ou tendo que aguardar um longo período para a implementação do seu direito. Além disso, há uma dificuldade do poder público municipal em 


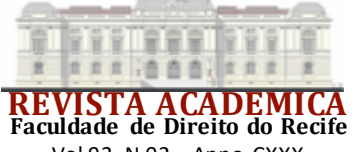

Vol.93 N.02 - Anno CXXX

atender essas demandas, tendo em vista a falta de uma previsão não apenas orçamentária, mas, também, operacional.

O cumprimento das ordens judiciais ensejará a realocação de verbas orçamentárias, para que seja possível a contratação de colaboradores - que não se restringe apenas aos professores, mas aos demais funcionários, como da limpeza, administrativo, da merenda -, a locação de imóveis, a realização de licitação para a aquisição de produtos e serviços (cadeiras, iluminação, material escolar), além de fatores ind ispensáveis à execução do serviço. Há, ademais, a necessidade de realização de concurso público, para a contratação dos servidores responsáveis pelo exercício das ativid ades tanto educacionais quanto administrativas.

A alta demand a no que toca esse direito implica a necessidade de reestruturação do serviço público, eis que não se está pleiteando apenas algumas vagas - que demandaria a alocação das crianças nas creches, ainda que houvesse um aumento do número máximo por sala -, mas um aumento substancial que não seria resolvido tão somente com a inclusão de mais alunos em uma mesma sala de aula.

Outro problema comumente verificado refere-se à falta ou insuficiência das condições legais em que se encontram as unidades prisionais. As demandas, ainda que decorrentes de litígio coletivo, propostas por um dos legitimados, como é o caso das Defensorias Públicas, visam, aprioristicamente, à indenização pela superlotação das penitenciárias, haja vista a violação a direitos fundamentais causadora de danos pessoais a detentos em estabelecimentos carcerários. Isso porque o Estado é responsável pela guarda e segurança das pessoas submetidas a encarceramento, enquanto permanecerem detidas, sendo seu dever mantê-las em condições carcerárias com mínimos padrões de humanidade estabelecidos em lei, bem como ressarcir os danos dele decorrentes (BRASIL, 2017d).

No entanto, a problemática envolvendo os estabelecimentos prisionais depende da definição e da implantação de políticas públicas específicas, providências de atribuição legislativa, administrativa e judicial. A adoção de medidas meramente indenizatórias perpetuaria a situação desumana que se constata nos estabelecimentos prisionais pátrios, motivo pelo qual o tratamento correto desse problema estrutural seria justamente um processo estrutural.

Outrossim, as demandas relativas aos tratamentos ou medicamentos no âmbito do Sistema Único de Saúde são exemplos de demandas estruturais, mas que são solucionadas de forma individual.

\section{A LEgItimidade do PODER JUdiciário NA CONDUÇÃo DO PROCESSO}

\section{ESTRUTURAL}

MONTES NETTO, Carlos Eduardo; PAIOLA, Jonathas Celino; FERREIRA, Olavo Augusto Vianna Alves. A RESOLUÇÃODE CONFLITOS ESTRUTURAIS NO SISTEMA MULTIPORTAS DE ACESSO À JUSTIÇA. Revista Acadêmica da Faculdade de Direito do Recife - ISSN: 2448-2307, v.93, n.2, p. 196-220 Out. 2021. ISSN 2448-2307. Disponível em: 


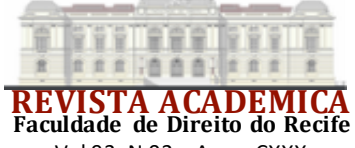

Vol.93 N.02 - Anno CXXX

Um dos pontos mais relevantes nessa discussão refere-se à intervenção do Poder Judiciário na atividade dos demais poderes, o que implica a violação do princípio da separação dos poderes. Isso porque, referido Poder, interfere em políticas públicas, imiscuindo-se, pois, tanto na tarefa do Poder Legislativo, quanto, sobretudo, na atuação do Poder Executivo.

No entanto, consoante jurisprudência prevalecente do STF e do STJ, a legitimidade do Poder Judiciário na implementação de políticas públicas deriva da violação dos direitos fundamentais e da função a ele atribuída de garantir a eficácia e a integridade dos direitos fundamentais, quando constatado o descumprimento do encargo constitucional atribuído, originariamente, aos poderes legislativo e executivo (BRASIL, 2010b, 2009b) ${ }^{8}$.

Há, por parte do Poder Judiciário, uma incumbência institucional na proteção dos direitos fundamentais e do Estado de Direito. Outro fator que corrobora a sua legitimidade refere-se à crise de representatividade do Poder Legislativo, associado ao fato de que as decisões relativas a questões polêmicas, nas quais existe um desacordo moral razoável, são relegadas ao Poder Judiciário, a fim de evitar desgaste na deliberação, como se verificou no julgamento do aborto anencéfalo e das uniões homoafetivas.

Nota-se, no contexto atual, uma judicialização da política, em que questões relevantes do ponto de vista político, social ou moral não são decididas pelas instituições tradicionais Legislativo e Executivo - sendo, todavia, transferidas e decididas, em caráter final, pelo Poder Judiciário.

Trata-se de um fenômeno global, a exemplo do que ocorreu nos Estados Unidos em que a Suprema Corte Americana definiu a eleição de 2000, entre Bush e Gore, além de invalidar, em outro julgado, os limites à participação financeira das empresas em campanhas eleitorais, ou em Israel em que a Suprema Corte decidiu sobre a constitucionalidade da construção de um muro na fronteira com o território palestino, na Colômbia em que a Suprema Corte julgou temas relativos à corrupção e mudança das práticas políticas, contenção do abuso das autoridades governamentais (BARROSO, 2018).

De mais a mais, em virtude do arranjo constitucional, incumbe ao referido Poder a função de colmatar as omissões inconstitucionais dos órgãos estatais ${ }^{9}$, adotando adotar medidas tendentes

8 "O acórdão recorrido, na hipótese, não destoa da jurisprudência desta Corte, quanto à inocorrência de violação ao princípio da separação dos poderes, eis que o julgamento, pelo Poder Judiciário, da legalidade dos atos dos demais poderes, não representa ofensa ao princípio da separação dos poderes, especialmente em se tratando de políticas públicas nas questões envolvendo o direito constitucional à saúde” (BRASIL, 2019d).

9 ““[...] A intervenção do Poder Judiciário, em tema de implementação de políticas governamentais 
a restaurar a norma fundamental violada pela inércia do poder público (BRASIL, 2006). O dever de proteção, pelo Poder Judiciário, em face de lesões oriundas do Poder Público e dos particulares, decorre da dimensão objetiva dos direitos fundamentais, que estabelece uma diretriz para a interpretação e aplicação das normas inscritas no ordenamento jurídico, com o escopo de assegurar os direitos fundamentais.

Outro problema enfrentad o na discussão da jurisd ição constitucional refere-se à limitação dos recursos públicos como justificativa para o descumprimento na implementação dos direitos sociais. No entanto, tem prevalecido o entendimento, no âmbito do STF, de que a reserva do possível:

[...] não pode ser invocada, pelo Estado, com a finalidade de exonerar-se do cumprimento de suas obrigações constitucionais, notadamente quando, dessa conduta governamental negativa, puder resultar nulificação ou, até mesmo, aniquilação de direitos constitucionais impregnados de um sentido de essencial fundamentalidade (BRASIL, 2004).

O que se defende não é a intervenção judicial em qualquer tema, mas, apenas, quando envolver direitos fundamentais ou os procedimentos democráticos, devendo, em outras hipóteses, ser deferente à discricionariedade do legislador e do administrador público, seja em decorrência da própria legitimidade democrática, assim como à falta de capacidade técnica e institucional no tocante a certas questões, que demandam um conhecimento, uma expertise específica, a qual é encontrada em órgãos públicos que foram criados justamente para a análise desses temas, como é o caso das agências reguladoras nas suas áreas específicas e o CADE.

\subsection{ESPÉCIES DE INTERVENÇÃO JUDICIAL}

É possível mencionar um primeiro tipo de intervenção judicial em políticas públicas, qual seja de simples implementação em que há expressa previsão constitucional e legal acerca do direito violado. É o caso, v.g., da garantia de "educação básica obrigatória e gratuita dos 4 (quatro) aos 17 (dezessete) anos de idade", previsto no art. 208 da CRFB/88. No mesmo sentido, é o previsto no art. $7^{\circ}, \mathrm{XXV}$, que trata da assistência gratuita aos filhos e dependentes desde o nascimento até 5 (cinco) anos de idade em creches e pré-escolas.

Nessa hipótese, havendo a falta de creches e pré-escolas, evidencia-se o direito, razão pela qual não há que se falar em violação ao princípio da separação de poderes. Pode-se citar, ainda, a

previstas e determinadas no texto constitucional [...] objetiva neutralizar os efeitos lesivos e perversos, que, provocados pela omissão estatal, nada mais traduzem senão inaceitável insulto a direitos básicos que a própria Constituição da República assegura à generalidade das pessoas" (BRASIL, 2011). 


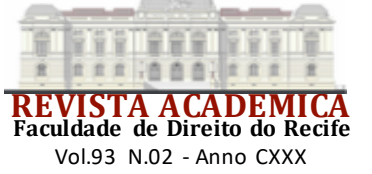

previsão expressa do prazo máximo para o Instituto Nacional do Seguro Social (INSS) decidir um requerimento de aposentadoria, que é de 30 dias, prorrogável por igual período, nos termos do art. 49, da Lei ${ }^{\circ} 9.784 / 99^{10}$.

A segunda espécie de intervenção judicial tem, por fundamento, a interpretação de princípios constitucionais que culminam na implementação de uma política pública. Exemplificativamente, o STJ, nos EDcl no REsp 1.657.156-RJ (BRASIL, 2018), com fund amento no direito à saúde, corolário do direito à vida, interpretando os arts. 5º, caput, e 196 da CF/88, decidiu que é possível a concessão dos medicamentos não incorporados em atos normativos do SUS.

Segundo a Corte Cidadã, não haveria violação ao princípio da separação dos Poderes, porquanto, uma das tarefas primordiais do Poder Judiciário, é atuar para a efetivação dos direitos fundamentais. Como asseverou o Ministro Edson Fachin no julgamento do ARE 947.823 AgR (BRASIL, 2016): “É firme o entendimento deste Tribunal de que o Poder Judiciário pode, sem que fique configurada violação ao princípio da separação dos Poderes, determinar a implementação de políticas públicas nas questões relativas ao direito constitucional à saúde".

No mesmo sentido, é o entendimento do STF, no julgamento do já mencionado RE 566.471, reconhecendo a obrigatoriedade de o Poder Público fornecer medicamento de alto custo. No caso, é importante destacar a preocupação do Min. Barroso com a necessidade de observância de um padrão procedimental, a partir do estabelecimento de um diálogo interinstitucional entre o Judiciário e entes ou pessoas com expertise na área da saúde:

[...] esse diálogo deve ser exigido, em um primeiro momento, para aferir a presença dos requisitos de dispensação do medicamento e, em um segundo momento, para determinar que os órgãos competentes (CONITEC e Ministério da Saúde) avaliem a possibilidade de sua incorporação no âmbito do SUS, mediante manifestação fundamentada a esse respeito.

Destarte, em que pese a ampla possibilidade de intervenção judicial visando a solução de problemas estruturais, especialmente no que se refere à concretização de direitos fundamentais, o próprio Judiciário vem reconhecendo a necessidade da promoção de um diálogo interinstitucional, visando a adoção de "soluções estruturais" que possam efetivamente solucionar o "problema estrutural".

\subsection{CONSEQUÊNCIAS DA INTERVENÇÃO JUDICIAL}

${ }^{10}$ Não se desconhece que no âmbito do RE 1.171.152 foi homologado acordo entre o MPF e o INSS no tocante aos prazos (BRASIL, 2021b). 
A intervenção judicial, ainda que em casos de fácil implementação, como o é da educação infantil, traz diversas implicações ao Poder Público. Vitorelli (2021) cita, como exemplo, as determinações judiciais ocorridas no ano de 2014 em Campinas, que somaram 3.068 crianças matriculadas.

Se a própria estrutura municipal não tem essa disponibilidade, a execução dessa medida dependerá da contratação de professores, que são recrutados por concurso público, bem como do fornecimento de alimentação, da alteração ou construção de estrutura física que comporte esse quantitativo de estudantes, além de mais insumos e de material escolar que não estavam, inicialmente, previstos no orçamento municipal.

Verifica-se que a implementação da medida judicial não decorre, simplesmente, da matrícula do aluno, haja vista o número de beneficiários pelas decisões judiciais. Deve-se ater, ainda, que a matrícula deve ocorrer em escolas próximas às residências das crianças, sendo mais um fator que dificulta a implementação da medida.

$\mathrm{Na}$ área da saúde, por exemplo, entre 2008 e 2017 houve um aumento de 130\% no ajuizamento de ações judiciais envolvendo o fornecimento de medicamentos ou tratamentos médicos, com o ingresso de 498.715 processos na primeira instância, distribuídos em 17 tribunais estaduais, 277.411 processos em segunda instância, distribuídos em 15 tribunais de justiça estaduais, gerando um impacto no orçamento do Ministério da Saúde em 2016 de R\$ 1,6 bilhão, representand o um aumento de 13 vezes nos gastos em atendimento a demand as judiciais (BRASIL, 2020).

A realocação desses recursos que estavam afetados a outras áreas poderá comprometer a prestação de serviços públicos, além de gerar possíveis implicações no que se refere ao cumprimento da Lei de Responsabilidade Fiscal, tendo em vista o aumento de despesa.

\section{A TUTELA EXTRAJUDICIAL DOS CONFLITOS ESTRUTURAIS}

A Lei no 7.347/85 (BRASIL, 1985), que disciplina a ação civil pública, prevê, como um dos legitimados para a sua propositura, o Ministério Público (MP), responsável pela maior atuação no âmbito da tutela coletiva. Isso porque o MP desempenha relevante papel na defesa dos direitos difusos, coletivos e dos interesses sociais e individuais indisponíveis, tanto que a CRFB/88 consagrou como instituição essencial à função jurisdicional do Estado (art. 127).

Essa atuação extrajudicial do MP é verificada a partir dos artigos $8^{\circ}, 9^{\circ}$ e 10 da Lei $n^{\circ}$ 7.347/85, que visa, a partir do inquérito civil, a obtenção de informações para embasar o 
ajuizamento da ação correspondente ou o seu arquivamento. $\mathrm{O}$ inquérito civil, cujo fundamento é retirado do art. 129, III, da CRFB/88, e disciplinado na Resolução nº 23/2007 (BRASIL, 2007a), do Conselho Nacional do Ministério Público (CNMP), tem por escopo a apuração de fato que possa autorizar a tutela dos interesses ou direitos.

Destaca-se que o inquérito civil não é condição de procedibilidade para o ajuizamento das ações a cargo do MP, porquanto é possível que o Parquet disponha de elementos suficientes para a propositura da ação correspondente sem a necessidade de outras investigações.

Verificou-se, no entanto, a necessidade de se utilizar outros mecanismos de solução dos conflitos coletivos, que não decorresse, exclusivamente, da propositura da ação ou do arquivamento do inquérito civil. Nesse cenário, exsurgem o compromisso de ajustamento de conduta, a recomend ação e o procedimento administrativo.

\subsection{PROCEDIMENTO ADMINISTRATIVO}

O procedimento administrativo, disciplinado pela Resolução 174/2017 (BRASIL, 2017b), do CNMP, é um dos instrumentos próprios da atividade-fim que se vale a instituição para acompanhar o cumprimento das cláusulas de compromisso de ajustamento de conduta celebrado, - acompanhar e fiscalizar, de forma continuada, políticas públicas ou instituições, apurar fato que enseje a tutela de interesses individuais indisponíveis e embasar outras atividades não sujeitas a inquérito civil (art. $\left.8^{\circ}\right)$.

Em virtude da sua amplitude e flexibilidade, é considerado um instrumento útil para acompanhar e fiscalizar reformas estruturais, haja vista que permite a proposição de soluções com a cooperação dos envolvidos, distanciando-se do caráter adversarial do inquérito civil, em que há a apuração de um ilícito em face de pessoas determinadas.

\subsection{RECOMENDAÇÃO}

A recomendação, segundo dispõe o art. $6^{\circ}, X X$, da Lei Complementar $n^{\circ} 75 / 93$, e a Resolução CNMP 164/2017 (BRASIL, 2017a), constitui um instrumento extrajudicial de atuação do MP:

[...] por intermédio do qual este expõe, em ato formal, razões fáticas e jurídicas sobre determinada questão, com o objetivo de persuadir o destinatário a praticar ou deixar de praticar determinados atos em benefício da melhoria dos serviços públicos e de relevância pública ou do respeito aos interesses, direitos e bens 


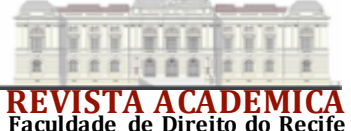

Vol.93 N.02 - Anno CXXX

defendidos pela instituição, atuando, assim, como instrumento de prevenção de responsabilidades ou correção de condutas.

Visa-se, com esse instrumento, além da correção do ato praticado, evitar a alegação, por parte do gestor público, do desconhecimento do fato objeto da recomendação. Trata-se de mais um instrumento na resolução de conflitos estruturais. No entanto, a recomendação, por si só, não será capaz de promover as alterações necessárias decorrentes de um conflito estrutural, notadamente pelo seu caráter unilateral.

Por outro lado, pode ser um instrumento idôneo a ensejar modificações se utilizada em conjunto com outras medidas, sobretudo com a participação dos atores envolvidos. Vitorelli (2021) cita interessante utilização da recomendação no bojo de um litígio estrutural cujo resultado fora positivo, qual seja a ação coordenada do Ministério Público Federal (MPF) que recomendou a todos os municípios e estados a implementarem o controle de horários dos médicos do sistema público de saúde, além da divulgação dos horários de cada profissional que atuariam no local, na medida em que um mesmo profissional pode trabalhar em diversos municípios e em turnos alternados de trabalho, o que dificultaria a comprovação da irregularidade, notadamente pela falta de um controle mais rígido.

Outro exemplo citado pelo autor é a recomendação estrutural proposta, outrossim, pelo MPF ao INSS com o fito de solucionar o atraso na análise de pedidos de benefícios previdenciários, em que foi proposta a adoção de providências de organizar a fila virtual de julgamento dos requerimentos apresentados, a publicação de critérios de ordenação dos requerimentos, dentre outras providências ${ }^{11}$.

Em decorrência da pandemia que assola o país, o MPF recomendou à Secretaria Especial de Atenção à Saúde Indígena (SESAI) a realização de testes de COVID na população indígena, para que fosse possível a adoção das medidas necessárias a fim de evitar a disseminação da doença nessa população vulnerável, demonstrando a possibilidade de utilização prática da recomendação visando a solução de problemas estruturais.

\subsection{COMPROMISSO DE AJUSTAMENTO DE CONDUTA}

O compromisso de ajustamento de conduta, nos termos do art. $1^{\circ}$, da Resolução CNMP $\mathrm{n}^{\circ}$ 179/2017 (BRASIL, 2017c), é um instrumento que visa salvaguardar direitos coletivos em sentido amplo e outros direitos “[...] cuja defesa está incumbido o Ministério Público, com natureza de

${ }^{11}$ Recomendação expedida nos autos do Procedimento Preparatório no 1.34.004.000791/2019-12. 


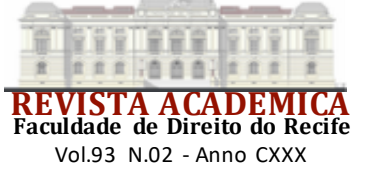

negócio jurídico que tem por finalidade a adequação da conduta às exigências legais e constitucionais, com eficácia de título executivo extrajudicial a partir da celebração", nos termos do art. $1^{\text {o }}$ da Resolução CNMP no 179/2017.

Trata-se de instrumento previsto, inicialmente, no art. $5^{\circ}, \S 6^{\circ}$, da Lei $n^{\circ} 7.347 / 85$, por meio do qual os órgãos públicos legitimados poderão tomar dos interessados compromisso de ajustamento de sua conduta às exigências legais. Não obstante a possibilidade de utilização do compromisso de ajustamento de conduta no âmbito de conflitos estruturais, Vitorelli (2021) cita alguns fatores que desestimulam a sua celebração, como a questão financeira - na medida em que o Estado e as grandes corporações dispõem de recursos suficientes para manter o processo judicial -, o desestímulo da incerteza do sucesso - porquanto não se pode afirmar que o acordo será, de fato, apto a solucionar o problema estrutural, além da necessidade de adoção de medidas de custo elevado -, o desestímulo pela incerteza da vinculação do acordo - a celebração do acordo não implica, necessariamente, a resolução definitiva da controvérsia.

No Brasil, pela amplitude dos colegitimados na propositura do compromisso, o problema é agravado, já que o acordo celebrado por um pode não ser aceito por outro, sendo possível, consequentemente, o ajuizamento da ação judicial. Sobre o tema, Mazzilli (2019) assevera que o compromisso consubstancia uma garantia mínima, não impedindo que os demais colegitimados proponham a ação civil, considerando que seria inconstitucional a estipulação de um limite de responsabilidade civil em favor do causador do dano por alguém que sequer é titular do direito violado. No caso de discordância de qualquer dos colegitimados ativos, ou autor propõe que:

Se a discordância à transação se verificar depois de ser esta homologada judicialmente, poderão os legitimados apelar, visando a elidir a eficácia da transação e sua homologação. Tratando-se de discordância manifestada antes da homologação judicial por um assistente simples, não obstará à eficácia do acordo; obstará, porém, se partir de assistente litisconsorcial ou litisconsorte (MAZZILLI, p. 520-521).

Por outro lado, o STJ já se posicionou, no julgamento do REsp nº 1.779.097/SC (BRASIL, 2019c), no sentido da não vinculatividade do acordo aos legitimados que dele não participaram se celebrado por ente que não tinha a atribuição sobre o bem jurídico tutelado. Por outro lado, haveria vinculação de todos os colegitimados se celebrado por ente que tinha a competência para tutelar o bem jurídico.

Não haveria, contudo, vinculação em se tratando de ajuizamento de ação civil pública que vise a anulação do compromisso, haja vista a deficiência de tutela do bem jurídico. Nessa hipótese, o compromisso poderia ser mantido válido em relação ao legitimado que o entabulou, devendo, 


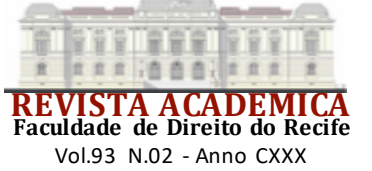

por conseguinte, o compromissário cumpri-lo, além de poder ser condenado na ação civil correspondente.

Essa não vinculação aos demais colegitimados pode ser constatada no caso do desastre do Rio Doce, em que a União, o Estad o de Minas Gerais e do Espírito Santo, além de outras entidades do Poder Executivo, ajuizaram uma ação civil pública, sendo, posteriormente, celebrado um compromisso de ajustamento de conduta. O MPF constatou que o acordo era deficiente, na medida em que não tutelou, adequadamente, o bem jurídico. Verificou, ainda, que havia um conflito de interesses, porquanto os entes públicos que o propuseram eram os mesmos responsáveis pela omissão na fiscalização. Em verdade, referidos entes deveriam ser, consequentemente, os réus na ação.

Como resultado, o MPF propôs a Ação Civil Pública 23863-07.2016.4.01.3800 (BELO HORIZONTE, 2016), asseverando a falta de tutela adequada e suficiente dos direitos coletivos afetados, seja pela ausência de participação efetiva das vítimas atingidas, seja pela limitação de recursos para a reparação dos danos causados, seja pela ausência de mecanismos efetivos no cumprimento das obrigações entabuladas. Não obstante às incertezas geradas na celebração do compromisso de ajustamento de conduta, não se trata de um instrumento hábil a promover as alterações estruturais necessárias num litígio coletivo. Isso porque o acordo propicia uma oportunidade de diálogo entre diversos atores, que, a partir de uma ampla discussão acerca do tema, podem chegar a uma solução consensual e, destarte, promover as alterações necessárias na estrutura.

E mais, o compromisso tem o condão de solucionar o problema de forma mais célere, se comparado com o procedimento judicial. A corroborar o exposto, Vitorelli (2021) cita um caso em que o Ministério Público do Estado de Goiás (MP-GO) propôs uma ação civil pública em 2006, em virtude dos problemas vivenciados pela população de um município do referido estado pelo tráfego intenso de caminhões, pela poluição sonora e pelos acidentes fatais. Referid a ação, até o presente momento, não teve o seu julgamento realizado pelo STF, não tendo sido, consequentemente, implementada a solução.

Por outro lado, o autor cita uma relevante ação civil pública estrutural, proposta pelo Ministério Público do Estado de São Paulo (MP-SP), que visou à redução dos índices de letalidade policial. Trata-se de um estudo realizado pelo Parquet bandeirante, durante 4 anos, com base em investigações que apuraram, efetivamente, os dados relativos a esse problema e que culminaram numa petição inicial de 203 páginas, embasada em um rigoroso diagnóstico, com a propositura de diversas providências para ser abordadas no plano de redução (VITORELLI, 2021). 
Para que um acordo seja eficaz e, por conseguinte, o bem jurídico seja tutelado,é imperioso que o problema seja conhecido com profundidade, que haja uma negociação efetiva entre os atores envolvidos, com a participação de ampla gama de interessados que possam contribuir para a solução do litígio, que haja transparência na condução do problema, possibilitand o o conhecimento de informações por parte das pessoas afetadas, que seja definido umplano de ação que seja possível de ser implementado, que viabilize a promoção das alterações necessárias, que haja um controle administrativo sobre a condução do plano de ação, a fim de que seja supervisionado, reavaliado e modificado, se não estiver alcançand o o seu objetivo, que os planos sejam detalhados, evitando incertezas quando da sua implementação.

Como exemplo da adoção desse importante instrumento, é possível mencionar o compromisso de ajustamento de conduta celebrado entre o MP-SP, pela Promotoria de Justiça do Patrimônio Público e Social da Capital, bem como pelo prefeito paulistano Bruno Covas, por representantes das empresas Flamingo e Albatroz, por representantes das associações Samorcc, Movieco e Amacon e pelos autores de duas ações populares.

De acordo com o TAC, as sociedades Flamingo e Albatroz doarão os imóveis que formam o Parque Augusta ao município de São Paulo e receberão títulos denominados TDC (transferência de direito de construir). Como havia sido ajuizad a uma ação civil pública pelo Parquet, em 2015, referidas duas empresas pagarão indenização de $\mathrm{R} \$$ 9.850.000,00, dos quais $\mathrm{R} \$$ 6.250.000,00 em serviços de construção do parque e do Boulevard da Rua Gravataí, sendo o restante empregado pelo município na manutenção do parque ( $\mathrm{R}$ \$ 2.000.000,00), na construção de um Centro de Convivência Intergeracional e na reforma de uma Instituição de Longa Permanência para Idosos (R \$ 1.600.000,00), da Secretaria Municipal de Assistência e Desenvolvimento Social, a pedido da Promotoria de Justiça dos Direitos Humanos da Capital.

Ademais, referido acordo prevê a liberação para o município de cerca de $\mathrm{R} \$ 90.000 .000,00$, obtidos mediante acordos firmados em 2015 entre o MP e prefeitura com os bancos UBS da Suíça e Citibank dos Estados Unidos da América, que visava à aquisição do Parque Augusta, com o objetivo de utilizá-lo na desapropriação de 22 terrenos para implantação de creches municipais, no início da construção de 12 CEUs (Centros de Educação Unificada) e na construção de sete EMEIs (Escolas Municipais de Educação Infantil) (SÃO PAULO, 2018).

Assim, o compromisso de ajustamento de conduta pode, observadas as ponderações feitas nesse tópico, contribuir para a resolução de problemas estruturais sendo, em alguns casos, até mesmo mais adequado do que o ajuizamento de uma ação civil pública.

\subsection{CONCILIAÇÃO E MEDIAÇÃO}




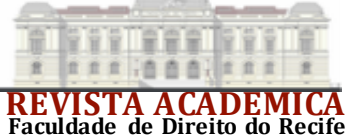

Vol.93 N.02 - Anno CXXX

Conforme já se destacou, o próprio CNJ, por meio da Resolução nº 125/2010, reconhece que o acesso à justiça "no art. $5^{\circ}, \mathrm{XXXV}$, da CRFB/88 além da vertente formal perante os órgãos judiciários, implica acesso à ordem juríd ica justa e a soluções efetivas”, dispondo ainda que:

[...] a conciliação e a mediação são instrumentos efetivos de pacificação social, solução e prevenção de litígios, e que a sua apropriada disciplina em programas já implementados no país tem reduzido a excessiva judicialização dos conflitos de interesses, a quantidade de recursos e de execução de sentenças;

Segund o Scavone Junior (2020, p. 287) “a conciliação implica na atividade de conciliador, que atua na tentativa de obtenção da solução dos conflitos sugerindo a solução sem que possa, entretanto, impor sua sugestão compulsoriamente, como se permite ao árbitro e ao juiz togado". Já a mediação, nos termos do parágrafo único, do art. $1^{\circ}$, da Lei nº 13.140 , de 26 de junho de 2015 (BRASIL, 2015b), é considerada "a atividade técnica exercida por terceiro imparcial sem poder decisório, que, escolhido ou aceito pelas partes, as auxilia e estimula a identificar ou desenvolver soluções consensuais para a controvérsia”. A propósito, Warat (2001, p. 80) consigna que:

A conciliação e a transação podem, em um primeiro momento, parecer com a mediação, mas as diferenças são gritantes. A conciliação e a transação não trabalham o conflito, ignorando-o, e, portanto, não o transformam como faz a medicação. O conciliador exerce a função de 'negociador do litígio', reduzindo a relação conflituosa a uma mercadoria. $O$ termo conciliação é um termo de cedência de um litigante a outro, encerrando-o. Mas o conflito no relacionamento, na melhor das hipóteses, permanece inalterado, já que a tendência é a de agravarse devido a uma conciliação que não expressa o encontro das partes com elas mesmas.

Nessa perspectiva, a mediação consiste na atuação de um terceiro imparcial nos casos em que houver vínculo anterior entre as partes, auxiliando os interessados a compreender as questões e os interesses em conflito, de modo que eles possam, pelo restabelecimento da comunicação, identificar, por si próprios, soluções consensuais que gerem benefícios mútuos (art. 165, $\S 3^{\circ}$, do Código de Processo Civil) (BRASIL, [2015a]), sendo possível que essa intervenção, em conflitos estruturais, seja realizada pelo próprio MP, em situações o problema decorra da má gestão de um serviço público (VITORELLI, 2021).

É o que ocorre no âmbito do Sistema Único de Saúde, em que o conflito entre os diversos atores, como os hospitais, os prestadores (médicos, enfermeiros, técnicos, dentre outros) e os colaboradores (fornecedores de insumos e matérias-primas) resulta na prestação de um serviço 
público de baixa qualidade aos usuários, com falta de medicamentos, atraso na realização das cirurgias, consultas que são desmarcadas, exames que não são realizados, entre outros.

A mediação poderia propiciar um diálogo entre as partes a fim de sanar as divergências que acabam prejudicando o próprio cidadão. Essa função do MP pode ser extraída da Resolução $\mathrm{n}^{\circ}$ 157/2018 (BRASIL, 2018), do Conselho Superior do Ministério Público do Trabalho (MPT), que instituiu o Núcleo Permanente de Incentivo à Autocomposição - NUPIA do Ministério Público do Trabalho, e que tem por finalidade atuar na implementação e adoção de mecanismos de autocomposição, como a negociação, a mediação e a conciliação, no âmbito do MPT.

Sobre o potencial prático da adoção dos métodos extrajudiciais de resolução de disputas, destaca-se a Câmara de Indenização 3054, criada em abril de 2008, como uma alternativa para que os familiares das vítimas do acidente aéreo envolvendo o voo 3054 da TAM, ocorrido em 2007 e que causou a morte de 199 pessoas, pudessem obter indenizações de forma mais rápida, sem ingressar no Judiciário, utilizando a metodologia de resolução de conflitos coletivos desenvolvida pela Universidade de Harvard, nos Estados Unidos, que contou com a atuação do Ministério da Justiça, por meio da Secretaria de Direito Econômico (SDE), da Defensoria Pública, do Ministério Público e do Procon, todos do Estado de São Paulo (BRASIL, 2009a; SÃO PAULO, 2009).

Referida Câmara funcionou por quatorze meses e encerrou as suas atividades com $92 \%$ de acordos fechados, resultando na indenização de 207 familiares de vítimas fatais do mencionado acidente aéreo. Foram protocolados 59 requerimentos na Câmara e apenas em 4 deles não houve acordo, tend o ocorrido a desistência em três casos antes da apresentação da proposta final e apenas uma proposta foi rejeitada. As indenizações foram pagas pela companhia aérea e sua seguradora no momento da assinatura dos acordos, ou após a sua homologação judicial, nos casos em que havia menores envolvidos (BRASIL, 2009a).

Até mesmo no âmbito da Administração Pública em geral tem sido cada vez mais incentivado o uso de métodos adequados de resolução de disputas diversos da Justiça estatal, abrindo espaço para a eleição da mediação e da conciliação nos mais diversos conflitos estruturais envolvendo os entes da Federação.

A Lei $n^{\circ}$ 14.133/2021 (BRASIL, 2021a) prevê no seu art. 138, II, que o contrato administrativo poder ser extinto "[...] por acordo entre as partes, por conciliação, por mediação ou por comitê de resolução de disputas, desde que haja interesse da Administração", estabelecendo o art. 151, ainda, a utilização de "meios alternativos de prevenção e resolução de controvérsias, notad amente a conciliação, a mediação, o comitê de resolução de disputas e a arbitragem”. Cumpre esclarecer que a análise da arbitragem para a resolução de disputas estruturais deve ser objeto de estudo específico que foge aos limites propostos no presente trabalho. 


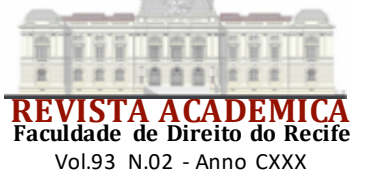

O Decreto $\mathrm{n}^{\circ}$ 9.760, de 11 de abril de2019 (BRASIL, 2019a), que dispõe sobre as infrações e sanções administrativas ao meio ambiente e estabelece o processo administrativo federal para a apuração destas infrações, prevê no seu art. 95-A que:

A conciliação deve ser estimulada pela administração pública federal ambiental, de acordo com o rito estabelecido neste Decreto, com vistas a encerrar os processos administrativos federais relativos à apuração de infrações administrativas por condutas e atividades lesivas ao meio ambiente.

Referido Decreto proporcionou a edição daPortaria Conjunta nº 1, de 07 de agosto de 2019 (BRASIL, 2019b), que institui o Núcleo de Conciliação Ambiental no âmbito do Instituto Brasileiro do Meio Ambiente (IBAMA) e do Instituto Chico Mendes de Conservação da Biodiversidade (ICMBio), competindo-lhe a realização de audiências de conciliação buscando “apresentar as soluções legais possíveis para encerrar o processo, tais como o desconto para pagamento, o parcelamento e a conversão da multa em serviços de preservação, melhoria e recuperação da qualidade do meio ambiente", nos termos do artigo 98-A, § 1º, inciso II, alínea "b", do Decreto ${ }^{\circ}$ 6.514/2008 (BRASIL, 2008).

Desta forma, mesmo em searas como a ambiental, que segundo Fazolli (2009) apresenta como características, dentre outras, o status de cláusula pétrea, a inalienabilidade e a preservação do meio ambiente como obrigação propter rem, tendo o próprio STF assentado que constitui direito fundamental típico de terceira geração, representand o prerrogativa jurídica de titularidade coletiva, que integra um processo de afirmação dos direitos humanos, correspondendo à expressão significativa de um poder atribuído não ao indivíduo identificado na sua singularidade, mas num sentido bastante abrangente, à própria coletividade social (BRASIL, 2005b), existem aspectos disponíveis que podem ser solucionados no âmbito extrajudicial.

A esse respeito, Ferreira, Rocha e Ferreira (2019) salientam as responsabilizações penal e administrativa, além da proteção ao meio ambiente no seu aspecto difuso não se enquadrariam no conceito de disponibilidade, mas a responsabilidade civil possui duas dimensões, uma coletiva e outra individual, possuindo essa última caráter privado e patrimonial que integram a esfera da disponibilidade dos indivíduos.

Destarte, em problemas estruturais como os que se verificam nas tragédias de Mariana e Brumadinho, indica-se a possível utilização da conciliação ou da mediação para a fixação de indenizações em favor das vítimas das tragédias, considerando que em casos semelhantes a via judicial não se mostrou adequada para a resolução desse tipo de disputa, especialmente diante da possibilidade da interposição de uma série e recursos que tornam imprevisível a duração das lides, 
a exemplo do conhecido caso envolvendo a disputa pelo Palácio Guanabara ${ }^{12}$, iniciado do Século XIX e transitado em julgado apenas em 2020.

\section{CONSIDERAÇÕES FINAIS}

O presente artigo buscou discorrer sobre as soluções que o sistema multiportas de acesso à justiça apresenta para a resolução dos denominados conflitos estruturais, que envolvem múltiplos aspectos e demandam a reorganização de toda uma estrutura, pública ou privada, muitas vezes de ambas, exigindo a adoção de soluções estruturais, por meio de um processo estrutural. Uma dessa portas de acesso à Justiça é o Poder Judiciário, diante do entendimento consagrado pela jurisprudência, inclusive do STF e do STJ, de que é legítima a intervenção da Justiça estatal na implementação de políticas públicas visando a concretização de direitos fundamentais, especialmente no caso de falha dos demais poderes no cumprimento das suas atribuições constitucionais.

No entanto, apesar de algumas vezes ser necessário, esse tipo de interferência judicial resulta em diversas implicações para a Administração Pública, a exemplo do que se destacou nesse estudo, como a criação de milhares de vagas em creches públicas, medida que depende da contratação emergencial de profissionais, fornecimento de alimentação, ampliação da estrutura física da rede municipal da realização de despesas que não estavam previstas no orçamento do Município, verificando-se situação semelhante no que se refere ao acesso aos serviços públicos de saúde.

Assim, observou-se a necessidade de se utilizar outros mecanismos de solução dos conflitos coletivos, diversos do processo judicial ou da promoção do inquérito civil pelo MP, como o compromisso de ajustamento de conduta, a recomendação, o procedimento administrativo, a conciliação e a mediação, ou até mesmo a combinação de mais de um método adequado de resolução de disputas, sem prejuízo, inclusive, do acesso ao processo judicial clássico, especialmente para a tutela de aspectos indisponíveis de determinados direitos, que não permitem a resolução da disputa pela via extrajudicial.

Nessa perspectiva, contemplou-se que a utilização dos instrumentos extrajudiciais de resolução de controvérsias diversos da Justiça estatal pode contribuir para a concretude de direitos

${ }^{12}$ A ação foi ajuizada em 1895 e o trânsito em julgado do processo ocorreu apenas em 2020, tendo o feito tramitado por três séculos distintos (AGÊNCIA BRASIL, 2020). 


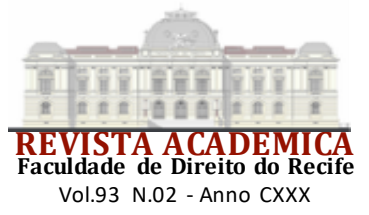

fundamentais envolvidos nos problemas estruturais, sobretudo ao possibilitar maior eficiência e celeridade no acesso à justiça.

Sugere-se, por exemplo, a possível utilização da conciliação ou da mediação para a fixação de indenizações em favor das vítimas das tragédias do rompimento das barragens de Mariana ou Brumadinho, como efetiva forma de acesso à justiça, diante da bem sucedida experiência com a Câmara de Indenização do voo 3054 da TAM, considerando que uma disputa judicial poderia se arrastar indefinidamente perante a Justiça estatal, deixando desamparadas, inclusive, pessoas hipossuficientes do ponto de vista financeiro.

Por fim, este estudo indicou a necessidade do desenvolvimento de novos trabalhos acadêmicos que se encarreguem de forma específica do potencial teórico e prático de cada um dos métodos extrajudiciais aqui tratados de forma ampla, dentro dos limites desta pesquisa.

\section{REFERÊNCIAS}

AGÊNCIABRASIL. Supremo decide que Palácio Guanabara pertence à União: Disputa judicial pela posse do imóvel começou em 1895. 02 set. 2020. Disponível em: https://agenciabrasil.ebc.com.br/justica/noticia/2020-09/supremo-decide-que-palacio-guanabarapertence-uniao. Acesso em: 05 jun. 2020.

ARENHART, Sérgio Cruz. A tutela coletiva de interesses individuais: para além da proteção dos interesses individuais homogêneos. 2. ed. São Paulo: RT, 2014.

BARROSO, Luís Roberto. Countermajoritarian, Representative, and Enlightened: The roles of constitutional tribunals in contemporary democracies. Revista Direito e Práxis, Rio de Janeiro, v. 9, n. $4, \quad$ out./dez., 2018. $\quad$ Disponível https://www.scielo.br/j/rdp/a/8FdmCG5b5vHMvTDHZyVvChh/?lang=en. Acesso em: 03 jun. 2021.

BELO HORIZONTE. 12 $2^{\mathrm{a}}$ Vara Federal de Belo Horizonte. Processo $\mathbf{n}^{\mathbf{0}} \mathbf{0 0 2 3 8 6 3 -}$ 07.2016.4.01.3800. Juiz: Mário de Paula Franco Júnior. 2016.

BRASIL. Conselho Nacional de Justiça. Resolução no 125 de 29/11/2010. 2010a. Disponível em: https://atos.cnj.jus.br/atos/detalhar/156. Acesso em: 04 jun. 2021.

BRASIL. Conselho Nacional de Justiça. Soluções construídas pelo CNJ buscam reduzir judicialização da saúde. 2020. Disponível em: https://www.cnj.jus.br/solucoes-construidas-pelocnj-buscam-reduzir-judicializacao-da-saude/. Acesso em: 03 de jun. 2021.

BRASIL. Conselho Nacional do Ministério Público. Resolução n 23, de 17 de setembro de 2007. 2007a. Disponível em: https://www.cnmp.mp.br/portal/images/Normas/Resolucoes/Resoluo 0232.pdf. Acesso em: 03 jun. 2021.

BRASIL. Conselho Nacional do Ministério Público. Resolução nº 164, de 28 de março de 2017. 2017a. 
https://www.cnmp.mp.br/portal/images/Resolucoes/Resolu\%C3\%A7\%C3\%A3o-164.pdf. Acesso em: 03 jun. 2021.

BRASIL. Conselho Nacional do Ministério Público. Resolução no 174, de 04 de julho de 2017. 2017b. Disponível em: https://www.cnmp.mp.br/portal/images/Resolucoes/Resoluo-174-1.pdf. Acesso em: 03 jun. 2021.

BRASIL. Conselho Nacional do Ministério Público. Resolução no 179, de 26 de julho de 2017. 2017c.

Disponível

em: https://www.cnmp.mp.br/portal/images/Resolucoes/Resolu\%C3\%A7\%C3\%A3o-179.pdf. Acesso em: 03 jun. 2021.

BRASIL. Conselho Superior do Ministério Público do Trabalho. Resolução $\mathbf{n}^{\circ}$ 157, de 28 de agosto de 2018. 2018. Disponível em: https://www.in.gov.br/materia//asset_publisher/Kujrw0TZC2Mb/content/id/40360096/do1-2018-09-11-resolucao-n-157-de-28de-agosto-de-2018-

40360062\#: :text=Institui\%20o\%20N\%C3\%BAcleo\%20Permanente\%20de,do\%20Minist\%C3

\%A9rio\%20P\%C3\%BAblico\%20do\%20Trabalho. Acesso em: 04 jun. 2021.

BRASIL. Decreto no 6.514, de 22 de julho de 2008. Diário Oficial da União. Brasília, 2008. Disponível em: http://www.planalto.gov.br/ccivil_03/_ato2007-2010/2008/decreto/d6514.htm. Acesso em: 05 jun. 2021.

BRASIL. Decreto n 9.760, de 11 de abril de 2019. Diário Oficial da União. Brasília, 2019a. Disponível em: http://www.planalto.gov.br/ccivil_03/_ato2019-2022/2019/decreto/D9760.htm. Acesso em: 05 jun. 2021.

BRASIL. Lein 7.347, de 24 de julho de 1985. Diário Oficial da União. Brasília, 1985. Disponível em: http://www.planalto.gov.br/ccivil_03/leis/17347orig.htm. Acesso em: 03 jun. 2021.

BRASIL. Lei $\mathbf{n}^{\mathbf{0}}$ 11.101, de 09 de fevereiro de 2005. Diário Oficial da União. Brasília, 2005a. Disponível em: http://www.planalto.gov.br/ccivil_03/_ato2004-2006/2005/lei/111101.htm. Acesso em: 04 jun. 2021.

BRASIL. Lei no 13.105, de 16 de março de 2015. Diário Oficial da União. Brasília, 2015a. Disponível em: http://www.planalto.gov.br/ccivil_03/_ato2015-2018/2015/lei/113105.htm. Acesso em: 04 jun. 2021.

BRASIL. Lei $\mathbf{n}^{\mathbf{0}}$ 13.140, de 26 de junho de 2015. Diário Oficial da União. Brasília, 2015 b. Disponível em: http://www.planalto.gov.br/ccivil_03/_ato2015-2018/2015/lei/113140.htm. Acesso em: 04 jun. 2021.

BRASIL. Lei no 14.133, de 01 de abril de 2021. Diário Oficial da União. Brasília, 2021a. Disponível em: http://www.planalto.gov.br/ccivil_03/_ato2019-2022/2021/lei/L14133.htm. Acesso em: 05 jun. 2021.

BRASIL. Ministério da Justiça. Câmara de Indenização 3054 termina com $92 \%$ de acordos fechados. 2009a. Disponível em: https://mj.jusbrasil.com.br/noticias/1682896/camara-deindenizacao-3054-termina-com-92-de-acordos-fechados. Acesso em: 07 jun. 2021. 
BRASIL. Portaria Conjunta $n^{0}$ 1, de 07 de agosto de 2019. Diário Oficial da União. Brasília, 2019b. Disponível em: https://www.in.gov.br/web/dou/-/portaria-conjunta-n-1-de-7-de-agostode-2019-210035607. Acesso em: 05 jun. 2021.

BRASIL. Superior Tribunal de Justiça (1. Turma). REsp 1.779.097/SC. Rel. Ministro Sérgio Kukina, 12 mar. 2019c.

BRASIL. Supremo Tribunal Federal. ADPF 45 MC. Relator(a): Min. Celso de Mello, 29 abr. 2004.

BRASIL. Supremo Tribunal Federal. ADI 3.540-MC. Relator: Min. Celso de Mello. 01 set. 2005b.

BRASIL. Supremo Tribunal Federal (2. Turma). ARE 639.337 AgR. Relator(a): Min. Celso de Mello, 23 ago. 2011.

BRASIL. Supremo Tribunal Federal (1. Turma). ARE 947.823 AgR. Rel. Min. Ed son Fachin, 28 jun. 2016.

BRASIL. Supremo Tribunal Federal (2. Turma). ARE 1.189.382 AgR. Relator(a): Min. Edson Fachin, 25 out. 2019 d.

BRASIL. Supremo Tribunal Federal. ED PET 3.388. Min. Luís Roberto Barroso, Tribunal Pleno, 23 out. 2013.

BRASIL. Supremo Tribunal Federal (2. Turma). RE 393.175 AgR. Relator(a): Min. Celso de Mello, 12 dez. 2006.

BRASIL. Supremo Tribunal Federal. RE 566.471 RG. Relator(a): Min. Marco Aurélio, Tribunal Pleno, 15 nov. 2007b.

BRASIL. Supremo Tribunal Federal. RE 580.252 RG. Relator(a): Teori Zavascki, Relator(a) p/ Acórdão: Gilmar Mendes, Tribunal Pleno, 16 fev. 2017d.

BRASIL. Supremo Tribunal Federal (2. Turma). . RE 595.595 AgR. Relator(a): EROS GRAU, 28 abr. 2009b.

BRASIL. Supremo Tribunal Federal. RE 1.171.152 Acordo. Relator(a): Alexandre de Moraes, Tribunal Pleno, j. 08 fev. 2021b.

BRASIL. Supremo Tribunal Federal. STA 175 AgR. Voto do Min. Celso de Mello, Relator(a): Min. Gilmar Mendes, Tribunal Pleno, j. 17 mar. 2010 b.

DIDIER JÚNIOR, Fredie; ZANETI JÚNIOR, Hermes. Curso de direito processual civil: processo coletivo. 15 ed. Salvador: Juspodivm, 2021.

DIDIER JÚNIOR, Fredie; ZANETI JÚNIOR, Hermes; OLIVEIRA, Rafael Alexandria de. Notas sobre as decisões estruturantes. In: ARENHART, Sergio Cruz; JOBIM, Marco Félix. Processos estruturais. Salvador: JusPodivm, 2017. 
FACHIN, Melina Girardi; SCHINEMANN, Caio Cesar Bueno. Decisões estruturantes na jurisdição constitucional brasileira: critérios processuais da tutela jurisdicional de direitos prestacionais. Revista Estudos Institucionais, v. 4, 1, 2018.

FAZOLLI, Silvio Alexandre. Bem jurídico ambiental: por uma tutela coletiva diferenciada. Porto Alegre: Verbo Jurídico, 2009.

FERREIRA, Olavo Augusto Vianna Alves. ROCHA, Matheus Lins; FERREIRA, Débora Cristina Fernandes Ananias Alves. Lei de Arbitragem: comentada artigo por artigo. Comentada artigo por artigo. São Paulo: Juspodivm, 2019.

KAUFMANN, Roberta Fragoso Menezes. Ações afirmativas à brasileira: necessidade ou mito? Uma análise histórico-jurídico-comparativa do negro nos Estados Unidos da América e no Brasil. Porto Alegre: Livraria do Advogado, 2007.

MAZZILLI, Hugo Nigro. A defesa dos interesses difusos em juízo. 31. ed. São Paulo: Saraiva, 2019.

SÃO PAULO. Ministério Público do Estado de São Paulo. Câmara de indenizações do acidente da TAM encerra atividades e apresenta balanço. 2009. Disponível em: http://www.mpsp.mp.br/portal/page/portal/noticias/publicacao_noticias/2009/ago09/C\%C3\%A2 mara $\% 20$ de $\% 20$ indeniza $\%$ C3\%A7\%C3\%B5es $\% 20$ do\%20acidente $\% 20$ da\%20TAM\%20encerra $\% 20$ ativida. Acesso em: 07 jun. 2021.

SÃO PAULO. Ministério Público do Estado de São Paulo. Justiça aprova acordo para criação do Parque Augusta. 2018. Disponível em: http://www.mpsp.mp.br/portal/page/portal/noticias/noticia?id_noticia=19307794\&id_grupo=118 . Acesso em: 05 jun. 2021.

SCAVONE JUNIOR, Luiz Antonio. Arbitragem: mediação, conciliação e negociação. 10. ed. Rio de Janeiro: Forense, 2020.

VITORELLI, Edilson. Manual de Direitos Difusos. Salvador: Editora JusPodivm, 2018.

VITORELLI, Edilson. Processo Civil Estrutural: Teoria e Prática. Salvador: Editora Juspodivm, 2021.

WARAT, Luis Alberto. O ofício do mediador. Florianópolis: Habitus, 2001. 